\title{
Site-specific soil microzonation for hazard resistant site and land use planning
}

\author{
S. Sah \\ Architectural Designer, Gensler, India
}

\begin{abstract}
Over the years, most of the urban complexes in India have undergone a phenomenal growth for various reasons and so has their vulnerability towards different hazards. Microzonation is thus a principal component of pre disaster mitigation efforts. Unless a detailed plot level microzonation is carried out for the city, it is not possible to prescribe detailed development guidelines and planning norms that will take into consideration the vulnerability of that land.

The methodology adopted here is to analyze the results of field reconnaissance surveys and soil borehole details and soil topography surveys, report on the very preliminary stages of the planning of towns/townships /institutional campuses and compare them against the priority index of various types of buildings that these sites constitute in order to have the following:

1. To provide the most appropriate soil conditions for the lifeline structures.

2. To prevent the project from decelerating in doing the above.

3. To reduce the negative effects of defunct urban planning in India because of outdated and ineffective development control regulations.

4. To facilitate the process of microzonation of the cities as a whole.

5. To facilitate strategic long term planning and to add to the pre-disaster mitigation efforts.

6. To help to reduce to a minimum the effects of construction on soil.

The urban planning framework in India has disappointingly not kept pace with the growth of cities, nor with the various changes that have come about in the way that planning is understood. The procedure that the research is trying to accomplish shall help to facilitate disaster mitigation efforts in India. The process involves more analytical work of the reports which is on general reports available for all major projects like strategic long term plans for the towns/townships/institutional campuses. Therefore, there shall not be much of a fiscal issue in doing so. The ultimate goal of the research is to define the
\end{abstract}


principles of site specific microzonation and account the role of an architect/ planner in contributing towards hazard mitigation efforts and strategies.

Keywords: geotechnical, seismic, reconnaissance, microzonation, priority index, architecture, urban planning, townships.

\section{An overview}

In India, growth of cities is managed by Master Development Plans, usually revised every 10 years. Typically, they determine the city's structural road network, land use zoning pattern, and development control regulations. Being regulatory and policy-oriented in nature, Master Development Plans are often not implemented. Most cities have outdated plans that do not respond to the demands of the real estate market.

Building regulations are intended to ensure the safety of buildings. However, the current development regulation system is irrational, complex, and ineffective-leading to abysmally low levels of compliance as substantial development happens outside the ambit of regulated development. This creates unsafe living conditions and increases vulnerability. Rationalizing and simplifying development control regulations and effective enforcement will improve compliance to regulations.

Over the years, most of the urban complexes in India have undergone a phenomenal growth for various socioeconomic reasons. Thus, the vulnerability of our cities for different hazards has also increased considerably, necessitating a proper hazard evaluation, particularly of the high population density urban center's laying in higher seismic zones. Seismic microzonation, thus, constitutes one of the principal components of pre-disaster mitigation effort.

\section{Origination}

By and large, the traditional planning framework has not been able to address holistically the issues related to the growth of cities. This is primarily because it has subscribed solely to the "physical growth alone" perspective. Hence, it has not been able to address issues related to safety and disaster mitigation. Factoring in the cost of disaster mitigation in urban and infrastructure planning in vulnerable areas is necessary to reduce the vulnerability of urban.

Areas. A paradigm shift from response to mitigation is urgently needed. These changes should include mitigation into the overall planning context. In a disaster, the survival of social and physical infrastructure systems is critical to the survival of the citizens. Urban infrastructure both physical and social is not designed to withstand hazards in most cities.

The methodology, now broadly accepted, follows a multidisciplinary hierarchical approach, where the sequence of studies aims to generate parameters for source, travel path, ground characteristics and vulnerability, and draw inputs from the disciplines of geology, geophysics, seismology, geotechnical engineering, engineering and seismology. 
The most important tool that is used for incorporating hazard consideration in land use zoning is microzonation. Unless a plot level microzonation is carried out for the city, it is not possible to prescribe detailed development guidelines and planning norms that will be taken into consideration the vulnerability of that land.

The local soil conditions have a profound influence on ground response during earthquakes. The recent destructive earthquakes have again demonstrated that the topography, nature of the bedrock and nature and geometry of the depositional soils are the primary factors that influence local modifications to the underlying motion. Based on the results of the geophysical as well as geotechnical investigations and laboratory testing, one or more idealized soil profiles must be selected for the site of interest.

\section{Methodology}

The methodology adopted here is to analyze the results of field reconnaissance survey, soil borehole details and soil topography surveys report in the very preliminary stages of planning of town/township/institutional campuses and compare it against the priority index of various types of building that these sites will eventually constitute, in order to have the following:

1. To provide the most appropriate soil conditions to the lifeline structures.

2. To reduce the negative effects of the defunct urban planning in India because of outdated and ineffective development control regulations.

3. To facilitate the process of microzonation of the cities.

4. To facilitate strategic long term planning and to add to the pre disaster mitigation efforts.

5. Help to reduce the effects of construction on soil to a minimum.

\section{Follow through (a sample implementation): soil microzonation of Arvind Residential Township, Ahmadabad, India}

\subsection{Introduction to the project}

Project name: Arvind Residential Township

Ownership: Arvind mills and textiles ltd.

Projected cost: land cost of $250 \mathrm{cr}$, with total project cost, for 9 million sq $\mathrm{ft}$ at 2000 per square feet, would be app. 1800-2000 cr

Adjacent land use: Arvind factory, Arvind mills, small industrial developments, rest agricultural.

Political authority: Ahmadabad Urban Development Authority. 


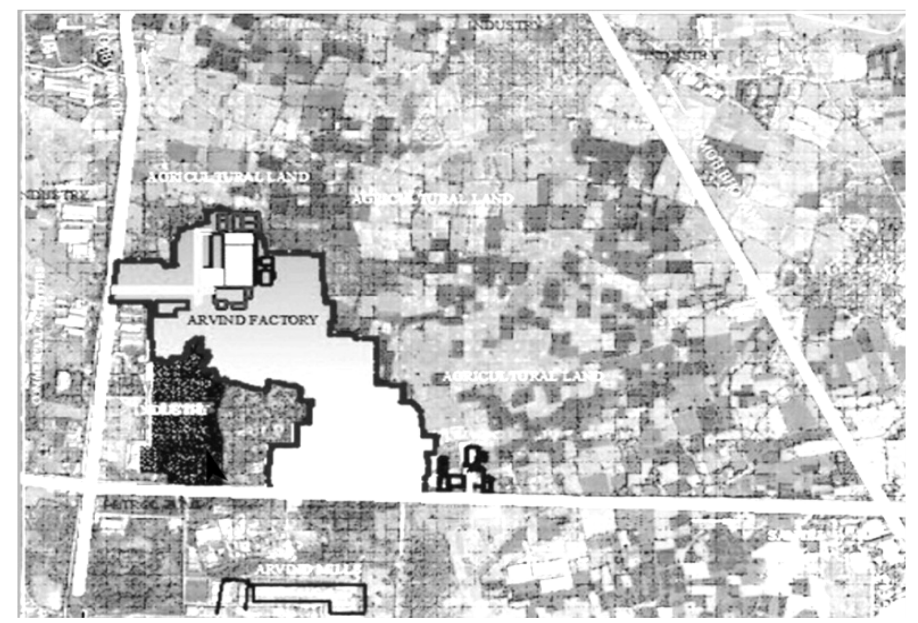

Figure 1: Key plan.

\subsection{Project requirements}

Low Income Housing: 1 RK, 1 BHK, 1 BHK Study.

Affordable: 2BHK S, 2 BHK M, 2 BHK L, 3 BHK S, 3 BHK L.

Executive Floors, Row House (executive units), Twin Bungalows (premium units), Villas (presidential units).

Amenities: School, Healthcare centre, Clubhouse, Community Centre, Retail Area.

\subsection{Priority index values by Ahmadabad Urban Development Authority}

With regard to land use zoning different types of buildings and utility services may be grouped under three priorities as indicated below:

Priority 1: Defense installation, industries, public utilities like hospitals, electricity installations, water supply, telephone exchange, aerodromes, railway stations, commercial centers, libraries, other building or installations with contents of high economic value.

Priority 2: Public institutions, Government offices, universities and residential areas.

Priority 3: Parks and play grounds, woodlands, gardens.

\subsection{Site details}

Plot Area: 134 Acres sq.m.

Limiting condition for development (bylaws).

$>$ FSI applicable on the land is 1.2.

$>$ Max. Ground Coverage permitted is $40 \%$.

$>$ Plot area reserved for crossover road $10 \%$.

$>>$ Plot area reserved for civic amenities 5\%.

$>>$ Open Space: Minimum 5\%. 


\section{Seismic Details:}

Seismic zone: zone 3.

Intensity VI-VIII.

Microzone: Ahmedabad micro zone D.

Accelerations from fault lines:

1. From Cambay fault: 5.6.

2. From Kutch fault: 7.1 .

History: the present structures indicate the effects of the 2001 earthquake as intensity VII.

\subsection{General investigation of seismicity and soil conditions at Ahmedabad}

Ahmadabad and surrounding areas are on the Sabarmati alluvial belt. The city is founded over deep deposits of cohesion less soils. The random distribution of the damage has been recorded from a number of localities scattered on the left and right banks of Sabarmati River. It is evident from the site investigation that the soil is loose up to $3 \mathrm{~m}$ depth and exhibits a relatively medium dense condition from $3 \mathrm{~m}$ to $15 \mathrm{~m}$ depths. The soil is silty sand throughout with a slight variation in the density from shallow to deeper depth. The natural moisture content varies from $8.51 \%$ at surface to $10.08 \%$ at $15 \mathrm{~m}$ depth with a degree of saturation ranging from $38.5 \%$ to $51.8 \%$.

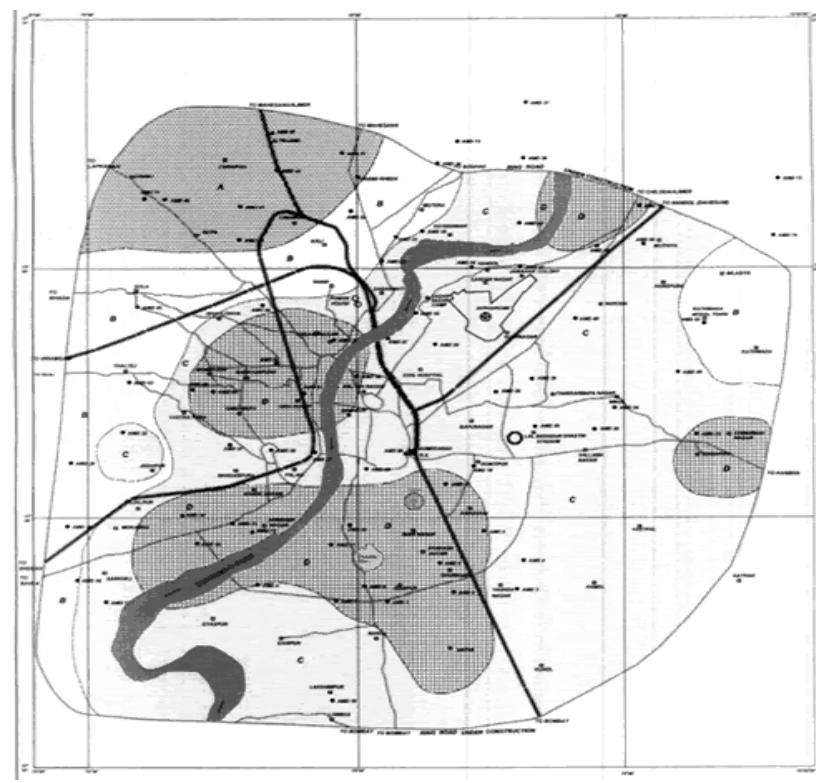

Figure 2: Preliminary seismic hazard map, $1^{\text {st }}$ level of microzonation of Ahmedabad City. 
The agglomeration is located in the Cambay graben that is occupied by $400 \mathrm{~m}$ thick Quaternary sediments. Though falling in Zone III of the Seismic Zoning Map of India, the city has been severely jolted by the distant Kutch earthquakes of 1819 and 2001. In case of the latter, some 120 taller structures collapsed, from which 718 people lost their lives. This vulnerability of the urban complex under the influence of long period seismic waves, as well as its importance as a rapidly growing commercial centre has necessitated a deeper understanding of the site characteristics on seismic excitation.

Three soil layers, identified based on resistivity survey are - loose topsoil, humid soil, and water saturated (bottom layer). P-wave velocity, as obtained from Hammer Seismic survey, for the three soil layers are $-200-300 \mathrm{~m} / \mathrm{s}$ for topsoil (thickness $<2 \mathrm{~m}$ ), 400 to $600 \mathrm{~m} / \mathrm{s}$ for the middle humid soil (thickness about $10 \mathrm{~m}$ ) and $600-1500 \mathrm{~m} / \mathrm{s}$ for the bottom layers lying below $12 \mathrm{~m}$. Based on the inputs from the present multi-disciplinary studies, the city of Ahmedabad has been demarcated into four seismic hazards micro zones A, B, C, and D.

Microzone $\mathrm{D}$ is anticipated to be the most hazardous while micro zone $\mathrm{A}$ is the least hazardous zone

GSI suggested carrying out of site-specific studies at each site during the design stage of high-rise buildings, in order to more accurately evaluate the site-specific conditions by planners, designers, and Ahmedabad Urban Development Authority.

\subsection{Site reconnaissance survey}

A detailed survey of the existing structures on the site was undertaken and also the surface samples were analyzed for basic soil type identification.

\subsubsection{Historical significance}

Rainfall records for the site: two months of heavy rainfall. Filling activities at the site: yes, sanitary filling, factory waste and frequent soil deposition.

Any previous developments: No.

\section{Presence of fill areas}

Type of fill (material): Stones, dry leaves, waste soil.

Extent of spread: $45 \mathrm{~m}$.

Location on the site: near to the factory.

Depth of fill: 2.5 - $4 \mathrm{~m}$ approx.

\subsubsection{Structure in the site}

Location: west, along the main road.

Purpose: Arvind factory.

Area: 7\% Existing condition.

$>$ Cracks: hairline cracks.

$>$ Surface condition: exposed brick, dilapidated.

$>$ Ground condition: no vegetation maintained.

$>>$ Corrosion /damp: yes.

$>>$ Condition of doors and windows: barely maintained. 
$>$ Electrical: self generation via on site power plant.

$>$ Water supply: do.

\subsubsection{Structure along the site}

Location: left and right side of the site.

Purpose: industrial unit.

Existing condition.

$>>$ Cracks: hairline cracks.

$>$ Surface condition: fair, due to newer construction.

$>$ Ground condition: no vegetation around.

$>>$ Corrosion /damp: along the pipelines.

$>$ Connection to the project: no.

> Services: 1. Drainage: same as the factory.

2. Electrical: do.

3. Water supply: do.

\subsection{Soil test data for the site}

Soil test data for the site is shown in Figure 3.

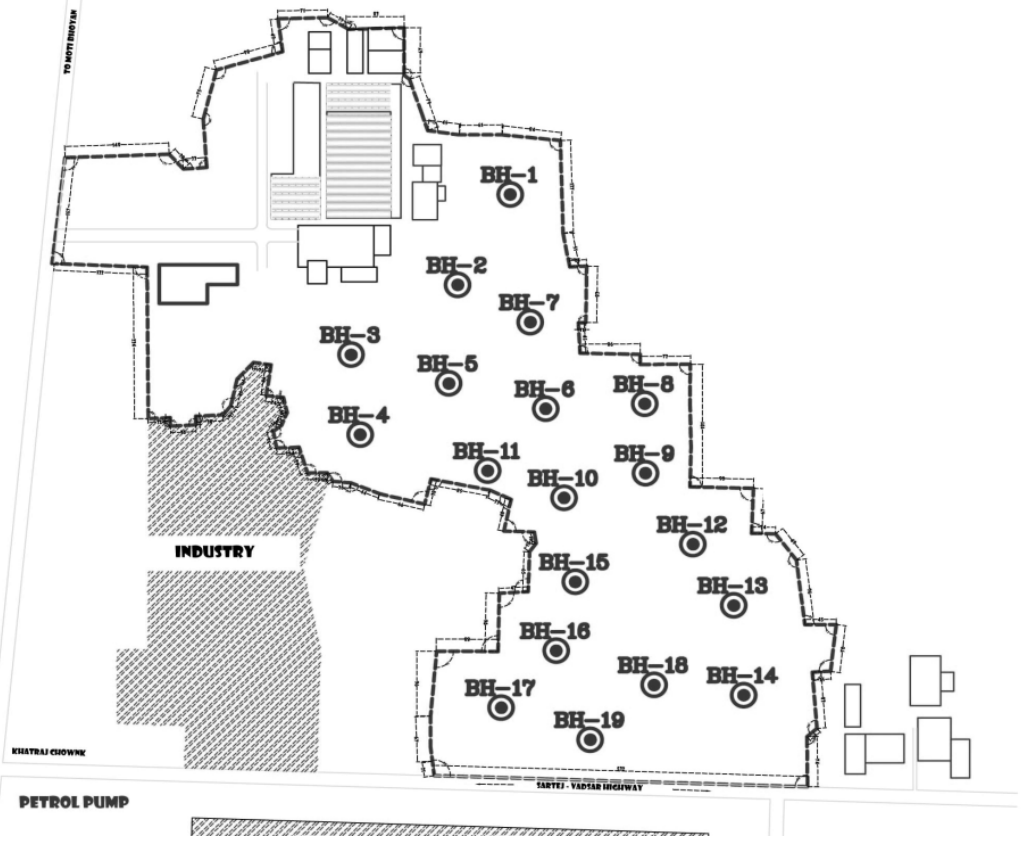

Figure 3: $\quad$ Soil test data for the site. 


\subsection{Site zonation according to soil test result and field reconnaissance survey}

Site zonation according to the soil test result and field reconnaissance survey is shown in Figure 4.

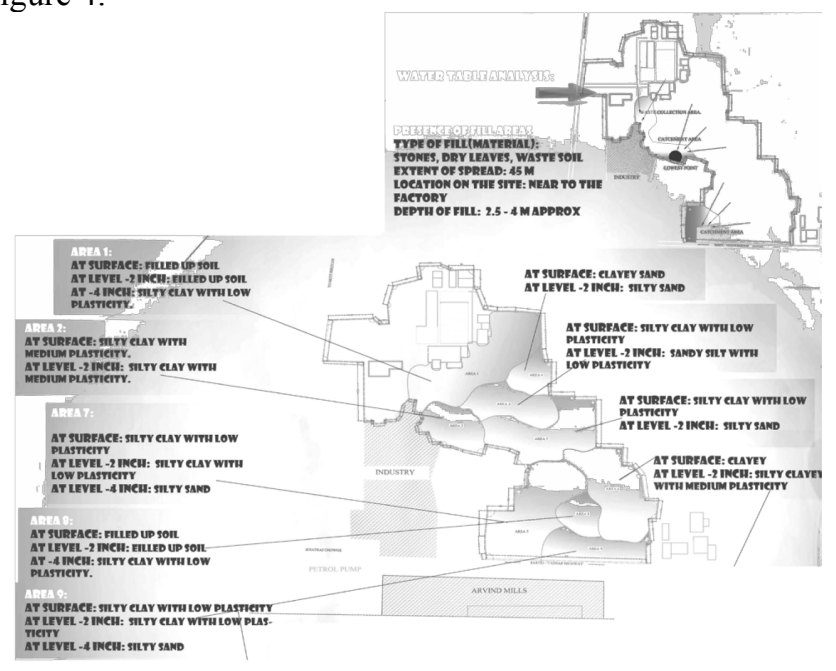

Figure 4: Site zonation according to soil test result and field reconnaissance survey.

\subsection{Architectural zoning inferences using the soil analysis and priority index values}

Soil specific site plan zoning is shown in Figure 5.

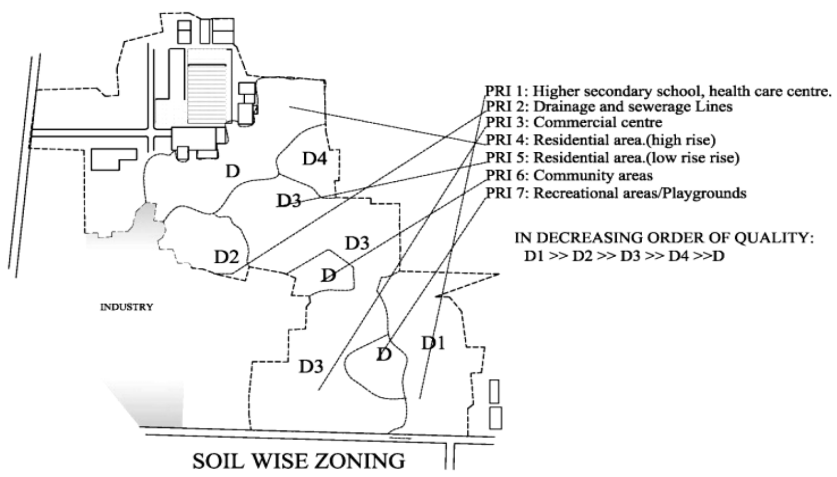

Figure 5: $\quad$ Soil specific site plan zoning. 
Therefore we achieve a zonation based on soil reports, field reconnaissance survey and prioritization

\subsection{Summing up of the steps}

\section{STEP 1: Field Recognizance Survey}

STEP 2: Document and Analysis According To Soil Properties

STEP 3: Studying the Bore Hole Detail Section and Analyzing according to the mechanical properties of the Soil sample.

STEP 4: Prioritize the structures in your design according to their priority index.

STEP 5: Compare the result of step 3 and step 4 in directly propositional manner.

\subsection{Details and analysis of the proposed procedure for soil wise zoning}

Priority index in Indian building byelaws esp. Ahmadabad Urban Development Authority bye laws categorize the various land uses and type of structure according to their function in decreasing order of Priority in terms of safety and cost analysis.

Field Reconnaissance is an important element in the procedure defined hereby. Subsequent to a review of the available data disclosed by the research described, and prior to the drilling of any exploratory holes, the proposed site should be thoroughly inspected by a geologist and/or a soils engineer. The primary objective of the reconnaissance is to obtain as much surface and subsurface information as possible without drilling exploratory holes or excavating test pits. The types of information to be obtained include accessibility of the site, topography, soil profile, bedrock litho logy and structure, and surface and sub- surface drainage. In determining soil and bedrock information, maximum use should be made of exposures occurring both naturally and as a result of construction.

Consolidation and settlement is one such area that needs attention. In saturated clay when the external pressure is provided, pressure is initially taken by the water then transferred to soil structure. Problematic soils like expansive or collapsible soil may cause high differential movements in structure as a result of settlements. Collapsible soil of value small than 1.0 do not create any problem while those having value more than 20 cause very severe problem. Sanitary landfills too have very less bearing capacity.

The soil activity of a place should become one of the parameter of soil zoning (microzoning of the site). In any moderate or large project having multi land use, the land use which comes under lifelines structure shall be located at a place where the soil is of best quality because of two reasons:

A. The life lines structures should be hazard resistant is all aspects, soil liquefaction, soil seismic activity etc, all should be taken care of.

B. If the soil zoning is not done, maybe in later phases of the project geotechnical reinforcement needs to be done to rectify this neglected aspect in initial stages of design, which in turn would require money and time to scrutinize the problem. 
Soil tests reports which basically comprises borehole sections and details, is required here to be analyzed by the experts and coordinated with the planner/architect so that he can examine them against the priority index value of the proposed structure and design/plan it accordingly.

The myth that the mitigation costs are high prevails over any decision of including such measures in major projects. The reality is that mitigation measures cost can be included for an additional cost of only $2 \%$ to $3 \%$. As of today most construction agencies do not consider disaster risk mitigation. It is rather a fact that the problem starts from the planning phase itself. If mitigation measures are taken into consideration it saves the project from getting scrutinized because of the problem that might occur later, thereby also saving the project from wasting money on the problems that arise therein. For example, suppose in a township project, a Lifeline structure (Hospital or a School), because of negligence in terms of hazard mitigation in the planning level, is placed on an expansive soil and while the foundation for the same is done it is found that geotechnical investigation needs to be done to rectify the problem, it will require more energy as well as scrutinize the project thereby increasing the costs tremendously. It thus proves that only if few small steps were added to the planning processes, it would have saved it from the losses. $2 \%-3 \%$ cost which goes for mitigation measures is thus negligible and in some cases acts as cost effective too. Township integrated development is a newfangled way of development. Researches' have proved them to be useful and sensitive to both local and urban level of environment. If soil sensitive analysis is done in preplanning stage of all of these upcoming townships it shall help the agencies involved in microzonation act and also ensure a safer environment

\section{Acknowledgements}

The present paper would not have been possible without constant help and support from Gensler, Bangalore Office, Birla Institute of Technology, Mersa, India; Indian Institute of Technology, Gandhinagar, India; National Information Centre for Earthquake Engineering, IIT Kanpur, India and Indian Seismological Institute, Gandhinagar, India. Specifically, I would like to thank the following individuals:

Dr. Sudhir K Jain, Director IIT Gandhinagar; Chairperson NICEE, IIT Kanpur.

Dr Amit Prashant, Professor, Civil Engineering, IIT Gandhinagar.

Dr Javed Malik, Professor, Civil Engineering, IIT Gandhinagar.

Vaibhav Shivare, Project Manager, Tata Housing, Gurgaon.

Dr. Shankha Pratim Bhattacharya, Asst Professor, Department of Architecture,

IIT Kharagpur.

Dr. Satyaki Sarkar, Reader, Department of Architecture, BIT Mesra.

Harshit Lakra, Reader, Department of Architecture, BIT Mesra.

Pallabee Choudhary, Scientist, Indian Seismological Institute, Gandhinagar.

Suresh Aaliawadi, NICEE, IIT Kanpur

Ar. Snigdha Sanyal, Reader, Department of Architecture, IIT Roorkee.

Mr. Parag Dave, M K Soil Testing Agency, Ahmedabad 


\section{References}

[1] BIS, Criteria for earthquake resistant design of structures (fifth revision). IS 1893, Part 1, 2002.

[2] Borcherdt, Wentworth R.D, Janssen. C.M, Fumal. A, T. and Gibbs, J.F. 1991, Methodology for predictive GIS mapping of special study zones for strong ground shaking in the San Francisco Bay region: Proceedings of the Fourth International Conference on Seismic Zonation, California, August 25-29 1991, v. 3, pp 545-552.

[3] Bye laws, Ahmadabad Urban Development Authority, Gujarat, 2004.

[4] IS 1893, Criteria for Earthquake Resistant Design of Structures, Bureau of Indian Standards, New Delhi, 2002, Part 1.

[5] DST, Report on seismic microzonation, 2007.

[6] Dharmaraju, R. Ramakrishna, V.V.G.S.T. and G. Devi Microzonation. Workshop, Bangalore. Proceedings. pp. 176-181, 2007.

[7] Seism tectonic Atlas of India and its Environs. Narula. P.L, Acharyya. S.K and Banerjee. J, (Eds.). Geol. Surv. India Spl. Publ. v. 59, p. 87, 2000. 